\title{
Renewable energy supervision and real time production control in Spain
}

\author{
T. Domínguez ${ }^{1}$, M. de la Torre ${ }^{1}$, G. Juberías ${ }^{1}$, E. Prieto ${ }^{2}$, R. Rivas ${ }^{1}$, E. Ruiz ${ }^{1}$ \\ ${ }^{1}$ Dpto. de Centro de Control Eléctrico (CECOEL) \\ Red Eléctrica de España SA \\ Pso. del Conde de los Gaitanes 177 \\ 28109-Alcobendas, Madrid, SPAIN. \\ Phone: ++34 916508500 Ext 3562; fax: ++34 9165045 42; e-mail: $\underline{\text { mtorre@ree.es }}$ \\ ${ }^{2}$ Dpto. de Estudios de Red \\ Red Eléctrica de España SA \\ Pso. del Conde de los Gaitanes 177 \\ 28109-Alcobendas, Madrid, SPAIN.
}

\begin{abstract}
The rapid growth of wind power, which has reached $13,908 \mathrm{MW}$ at the end of 2007, along with the installation of other technologies like solar power, mini-hydraulic or cogeneration plants have lead to the consideration of special regime ${ }^{1}$ generation as another major fraction of the Spanish electrical generation mix. In order to supervise, control and integrate the Spanish TSO (Red Eléctrica de España) has launched in June 2006 the Control Centre for Renewable Energies (CECRE) which deals with the specific challenges of these technologies with the goal of maximizing their production without jeopardizing the security of the electric system.
\end{abstract}

\section{KEY WORDS}

Renewable energy, system operation, voltage dip, control centre, wind power

\section{INTRODUCTION}

Special regime generation accounts for $27 \%$ (January 2008) of the installed capacity in the Spanish peninsular system in terms of power and has produced $20 \%$ of the electrical energy in 2007. These values have been increasing at a fast rate for the last years and this tendency is expected to continue far in the future as foreseen by the Renewable Energies' Plan for Spain [1] complying with European directives [2].

\footnotetext{
1 Special regime generation is defined as those technologies which receive an economical incentive established by the RD 661/2007 [1]. Includes wind power, cogeneration plants, photovoltaic and thermoelectric solar power, mini-hydraulic, biomass etc $(\mathrm{P}<=50 \mathrm{MW})$.
}

The benefits of renewable energy production are many (no air pollution, no CO2 emissions, benefits in rural areas, no dependency on outside primary energy resources...) and they are well known by society as a whole. However, integrating these technologies in the electric system has become a challenge to system operators throughout the world due, for example, to their special dynamic behaviour, their difficult prediction hours ahead or the size and location of the facilities.

Wind energy requires special attention since it is the biggest and fastest growing share of the special regime generation reaching a total of 13,908 MW installed capacity at the end of the year 2007. Wind power introduces various novelties for the electric system such as the use of power electronics in the generating units or prediction uncertainties due to the variable nature of its primary resource.

As an approach for maintaining system security system operators have paid great attention to off-line studies determining the maximum special regime production and specially wind generation that the power system is able to integrate under security conditions. These studies are based on particular cases which can be identified as representative and normally lead to strict limitations, in order to assure system security in all cases and could put the system at risk in very special situations.

As an example, one measure that has been introduced out of these studies in order to achieve the integration of wind generation into 
the system consists on a new grid code which has been proposed and approved.

The main step towards harmonizing special regime generation and system security in real time is the commission of a new control centre specifically for renewable energies called CECRE. This control centre, which focuses mainly on wind power, and its main functions are described in this paper.

The CECRE complements these off-line studies and provides the required tools and infrastructure to determine such limits also in real time maximizing renewable energy production and assuring security at all times.

One of the main applications running behind the CECRE is called GEMAS, acronym in Spanish for Maximum Admissible Wind Power Generation in the System. GEMAS focuses in wind power and has been designed to calculate in real time (every 20 minutes and assuming certain hypotheses) the maximum wind power production that the system is able to cope with at a given moment fulfilling certain security criteria and determines, if needed, the maximum production limits to be applied by each wind farm.

\section{PROBLEMS WITH RENEWABLE ENERGY INTEGRATION}

There are various concerns regarding the integration of renewable energy in Spain: transient stability of wind power after voltage dips originated by a correctly cleared fault, power balance viability with high renewable production in the entire Spanish peninsular system, localized congestion management and voltage control.

\subsection{BEHAVIOUR OF WIND GENERATION DURING VOLTAGE DIPS}

Since wind power production acquired a certain level of importance, simultaneous wind power generation losses synchronized to correctly cleared system faults have been observed. The sensitive protection devices installed in the present wind turbines in service in the Spanish electric system are responsible for this behaviour. In some cases protections may trip the wind farm if the voltage at the connection point varies abruptly for more than $10 \%$ of the nominal voltage even for the shortest of faults. Some faults generate voltage dips that can be greater than $10 \%$ of the nominal voltage for buses hundreds of kilometres away from where the fault occurred as the Spanish network is robust and well meshed. As a consequence of these voltage dips large quantities of wind turbines may trip simultaneously since most wind farms in Spain are directly connected to the transmission voltages (400 and $220 \mathrm{kV}$ ) or high distribution voltages (132 or $110 \mathrm{kV}$ ). Figure 1 shows an example of the propagation of a fault caused voltage dip. In most of the $400 \mathrm{kV}$ peninsular system its depth is greater than $10 \%$ (360 kV voltage level line).

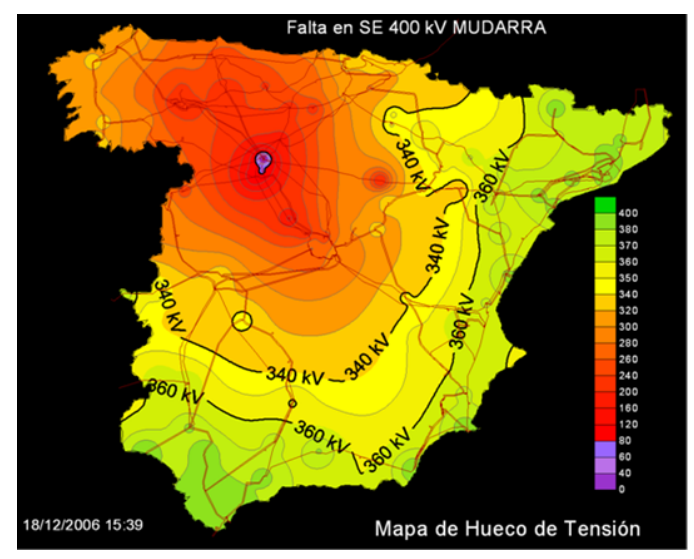

Fig.1. Example of voltage dip propagation due to a fault.

Figure 2 shows the wind power production on May 7th 2007. On this day a number of weather caused faults occurred in the system leading to several wind power trippings. The assets affected and the values of the generation loss are shown.

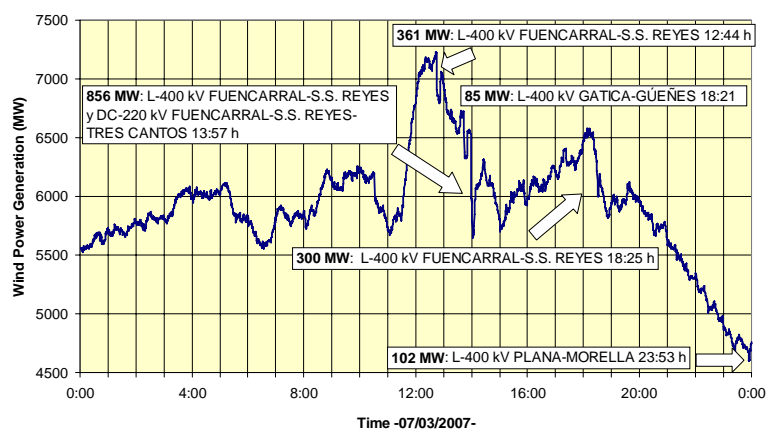

Fig. 2. Wind generation losses on March $7^{\text {th }} 2007$.

Being aware of this drawback, REE undertook a transient stability study [3] of the response of wind energy generation to voltage dips in order to determine the maximum wind energy production of the Iberian Power System in peak and off-peak periods. The results of the study defined the voltage ride-through requirements 
and the permissible active and reactive consumption values during voltage dip situations which were then gathered in the grid code.

\subsection{POWER BALANCE FEASIBILITY AND REQUIREMENT RATIO}

Another main difficulty regarding renewable energy integration lies on its production variability since it comes in most cases from an unmanageable primary resource. It is necessary to ensure the electrical supply at all times taking into account all operational circumstances and the technical limitations of the minimum indispensable manageable power plants.

With the goal of analyzing the influence of nonmanageable production on the rest of the manageable generation a new variable is monitored: the requirement, which accounts for the instantaneous production that must be put out in the system by manageable energy resources in order to properly carry out the demand coverage. The requirement results from subtracting the instantaneous wind production to the load (other renewable resources are still not taken into account on this calculation) and its most interesting feature is the ratio between the daily peak requirement and the lowest daily requirement. Figure 3 shows the monotonous curve of the daily requirement ratios compared to the same monotonous curve for the demand peak/off-peak ratio for 2007. Figure 4 shows the monotonous curves of the requirement ratio for 2004, 2005, 2007 and 2007

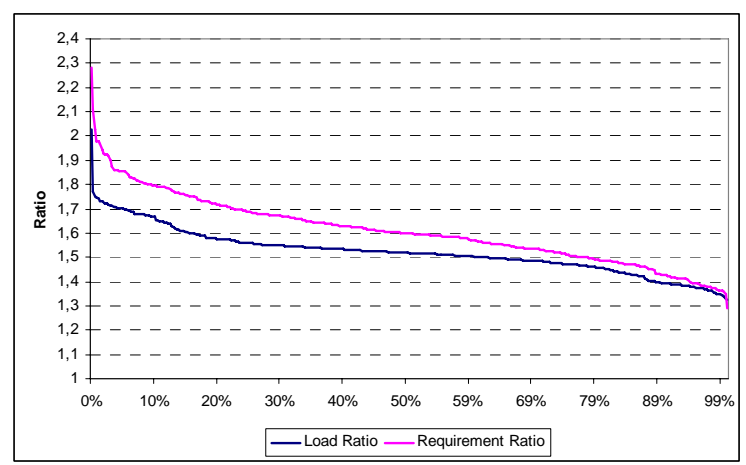

Fig.3. Daily requirement ratio compared to daily load ratio for 2007.

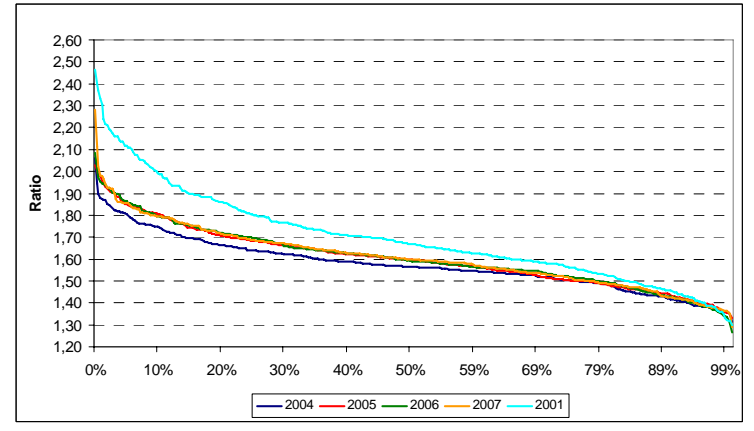

Fig. 4. Daily requirement ratios in 2004, 2005, 2006, 2007 and expected in 2011.

It can be observed in figure 3 that wind energy contributes to steeper manageable generation ramps some days more than it smoothes other days' ramps, since it is generally at night when daily high wind productions are reached. As wind production increases over the years the yearly highest requirement ratios also increase. The expected monotonous daily requirement ratio curve for 2011 is also represented in figure 4. This curve has been obtained from extrapolation of current wind power behaviour to expected installed capacity.

Due to technical minimum power output of generating units, flowing hydro power plants and other reasons there is a requirement ratio over which it is necessary to shut down conventional power generation during off-peak hours to connect it back several hours later in real time to cover the peak demand. It is estimated that this ratio lies around 2 for the Spanish electric system. Several combined cycle power units were shut down in real time six times in 2006 and one time in 2007 to recover downward tertiary reserves in the system.

As some power plants have longer start-up times, real time disconnection and short connection afterwards may not longer be possible above certain daily requirement ratios. In addition, special regime generation will not provide by 2011 ancillary services to the system so some manageable generation will have to be kept connected to provide primary, secondary and tertiary reserve as well as active voltage support. This means there is also a limiting requirement ratio above which renewable energy reduction may be unavoidable.

The uncertainty introduced by forecast errors in wind power production within the time scope between lowest off-peak requirement and highest peak requirement will have to be taken 
into consideration to determine the minimum manageable generation necessary at off-peak periods.

A key issue in renewable energy integration regarding power balance feasibility is the amount of hydro-pump storage units available in the system. In Spain there are about 4,800 MW installed, but there are several projects in the planning phase that would increase substantially this figure in the future.

\subsection{SPECIAL REGIME EVACUATION CONGESTION MANAGEMENT}

Although wind farms are relatively well spread within the system and the transmission network is robust, several situations have arisen where renewable energy reduction in real time has been inevitable due to congestions in the distribution or transmission network. Due to this reason, 23.4 GWh of wind production have been reduced in real time (in 2007), which represents the $0.09 \%$ of the total wind production within this period.

\subsection{VOLTAGE CONTROL}

The Spanish regulation currently in force [4] establishes a bonus or penalty depending on the reactive power system factor for the special regime generation. Table 1 shows the values of power factor and the percentage value of incentive/penalization to be applied in the different daily periods.

This non-continuous voltage control procedure implies in practice the simultaneous connection/ disconnection of capacitors when there is a change in the period (peak, off peak or intermediate) as the producer's goal is to achieve the maximum reactive bonus in each of these periods. The sudden change in the reactive power is the cause of abrupt changes in the voltage profile of certain substations where numerous wind mills are connected to, and has lead several days to the tripping of wind generation due to the activation of its overvoltage protections.

New continuous voltage control systems and incentives must be developed and introduced in order to avoid voltage control related problems in the network.

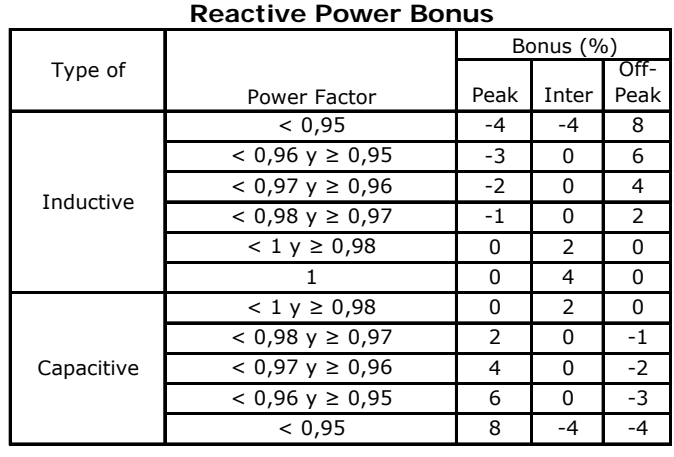

Table. 1. Bonus/penalty reactive power system.

\section{CONTROL CENTER FOR RENEWABLE ENERGIES (CECRE)}

The CECRE (figure 5) was commissioned in June 2006 and was put into service to achieve a greater supervision and control of special regime generation which would then help to reach a higher level of integration of these renewable energy sources. The special regulation regime includes wind, solar and small hydro power, cogeneration plants and other renewable generation. CECRE's main function is to manage and integrate the special regime production depending on the needs of the electrical system.

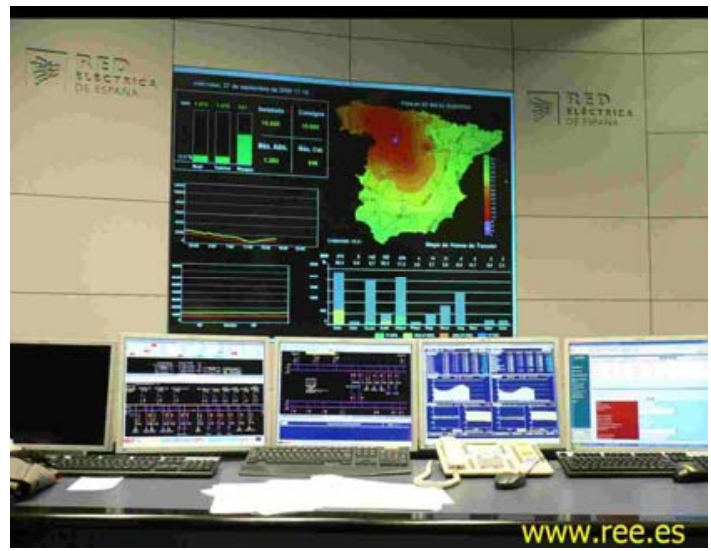

Fig. 5. General view of the CECRE.

According to the regulation from June 30th 2007 [3] all production facilities with a total installed power greater than $10 \mathrm{MW}$ must be controlled by a control centre that is directly connected to the CECRE. These renewable energy control centers (WGCCs) must have enough control over the plants in order to be able to execute CECRE's orders within 15 minutes at all times (figure 6). 


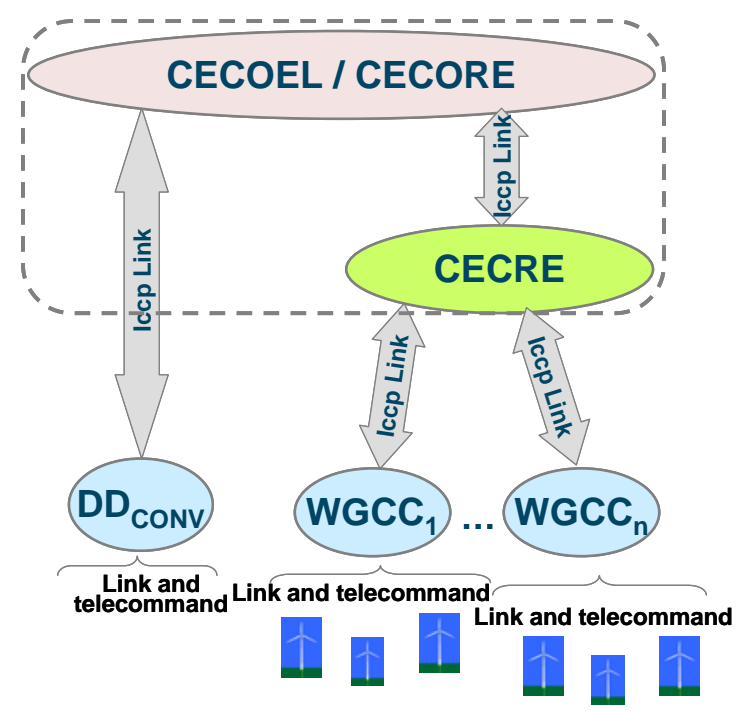

Fig. 6. Functional scheme CECRE and Wind Generation Control Centers (WGCC).

This control and supervision scheme yields improved security and effectiveness in system operation and substitutes permanent conservative hypothesis and preventive criteria for real time production control, allowing higher energy productions and therefore higher profitable installed power. A new computer application (GEMAS) was developed in order to accomplish this objective with wind generation. The maximum production limit calculated by GEMAS for each wind farm is issued by CECRE to the WGCCs .

\section{MAXIMUM ADMISSIBLE WIND POWER GENERATION IN THE SYSTEM (GEMAS)}

GEMAS fills the gap in the field of real time transient stability assessment applications that could, with certain simplifications, provide confident limitations depending on the real-time scenario, allowing higher wind productions most of the time.

GEMAS carries out every 20 minutes three phase dead faults in the bus bars of 70 different substations. Satisfactory results are obtained using pseudo-dynamic or 'switching studies' with static power flow applications. Generation units are modified to Norton equivalents and loads are converted to constant admittance models as well. The generation loss is estimated by comparing residual voltage at the wind farm connection buses with the sensitivity of the turbine technology since technology information of every wind turbine connected to the network is known. The production of every wind farm connected to the CECRE is received in real time with the help of the ICCP links to the WGCCs.

Simulation results are continuously being checked with real faults and are found to be consistent in three phase dead faults and conservative in single- or bi-phase faults when faults are shorter or equal to $100 \mathrm{~ms}$ (Table 2).

\begin{tabular}{|lcc|}
\hline \multicolumn{1}{|c}{ FAULT } & $\begin{array}{c}\text { REAL POWER } \\
\text { LOSS (MW) }\end{array}$ & $\begin{array}{c}\text { SIMULATED } \\
\text { POWER LOSS } \\
\text { (MW) }\end{array}$ \\
\hline L-400 kV HERNANI-ARGÍA & 606 & 710 \\
\hline $\begin{array}{l}\text { DC-400 kV OLMEDILLA- } \\
\text { ROMICA }\end{array}$ & 685 & 729 \\
\hline $\begin{array}{l}\text { AT-2 400/220 kV } \\
\text { ESCOMBRERAS }\end{array}$ & 885 & 921 \\
\hline
\end{tabular}

Table 2. Real vs. Simulated Power Losses

With the help of this methodology, the most severe wind power trippings due to voltage dips that could take place in the Spanish peninsular system are calculated every 20 minutes. In case one or several contingencies produce a wind power tripping that would put the tie lines with France at risk ${ }^{2}$, the application searches the wind production profile that achieves the maximum wind production with an admissible power loss at every critical contingency.

Two separate lineal optimization problems are solved in order to obtain the limitations for each wind farm. The first loop runs with wind production as the optimization goal and is subject to the constraints that no contingency can lead to a wind power loss greater than the admissible one and the production for every wind farm must not be greater than its actual production.

The solution to this problem is not unique and a second optimization loop is needed to select which of the possible solutions that maximize wind production keeps the system in its safest state. Thus, the objective minimization function for this second optimization problem is the sum of the wind power losses for all critical and

\footnotetext{
${ }^{2}$ In case of generation tripping, around $90 \%$ of the primary power regulation flows into the Spanish system through the interconnection with France. If the wind power loss exceeds the admissible value, these tie lines might also trip leading to the isolation and possible collapse of the Iberian system due to generation-load unbalance.
} 
pseudo-critical contingencies ${ }^{3}$. The solution of the first loop is used as a constraint in this second process. The limitations of wind farms with a positive reduced gradient of their 'power' variable in the first problem are released to their installed power since a raise on their production would increment the maximal allowed wind production.

Upon completion of the second optimization loop an initial set point for every wind farm is obtained. In order to preserve time continuity of the solution some filters are applied assuming a compromise between mathematical precision and system security. Filters avoid as well sudden variations of wind production in both directions which would lead to secondary reserve consumption and additional risks to system security.

Finally, the set points of those wind farms with the same technology, control centre and connection node are added to comply with the approved regulation [5] and sent through the EMS system to the WGCCs both as single park and aggregated set points. Control centres may distribute the reductions between the wind parks in the aggregated limit.

\section{CONCLUSIONS}

Renewable energy in Spain has reached high penetration levels and these levels will continue to rise at least in the next several years. Managing these new technologies and specially wind power is more difficult than conventional generation management due to their primary resources, most of which are not controllable and to the large number of smaller plants compared to conventional generation. Additionally, the stability of the electrical machines involved in the case of wind power, which were developed for lower levels of wind penetration than those achieved in Spain, could represent a menace for system security if risks are not checked and managed properly.

In order to achieve higher levels of renewable energy penetration a new Control Centre for Renewable Energies (CECRE) has been set into service. The CECRE is mainly focused on wind generation and accomplishes the vital task of

\footnotetext{
${ }^{3}$ Pseudo-critical contingencies are those that produce a wind power loss greater than the admissible value minus a defined margin, normally of $200 \mathrm{MW}$.
}

communicating, both via ICCP and via telephone, with the generating companies' wind generation control centers (WGCCs). These facilities must provide effective control of the turbines and enough capability to follow the limitations and instructions issued by CECRE in order to achieve true real-time management opportunities.

Inside CECRE, the application GEMAS makes real time simulations possible and therefore adapts preventive criteria to more permissive limitations depending on the real time scenario. At the same time GEMAS eases the operator the task of limiting wind generation in real time due to compromised system security either in case $\mathrm{N}-1$ criteria are not met as a consequence of an incident or in case reduction is necessary because of power balance feasibility problems.

For the near future, integration of wind generation regarding transient stability will be facilitated as wind farms adapt their turbines to the new grid code, but as more and more facilities start operating, limitations due to power balance feasibility or congestion might become more frequent especially if planned reinforcement of the transmission network is delayed by local opposition. Furthermore, if the installed capacity exceeds further into the future the 20.000 MW milestone it may be necessary to add new requirements to the "grid code" in order to maintain system stability.

\section{BIBLIOGRAPHY}

[1] "Plan de Energías Renovables para España, 2005-2010” IDAE.

[2] Directive 2001/77/CE on the promotion of the electricity produced from renewable energy sources in the internal electricity market. European Parliament and Council Sept. 21 $1^{\text {st }}$ 2001.

[3] Francisco Rodríguez-Bobada, Antonio Reis, Alberto Ceña, Elizabeth Giraut, "Study of wind energy penetration in the Iberian peninsula” in Proc. EWEC 2006 (Athens).

[4] REAL DECRETO 661/2007, de 25 de mayo, por el que se regula la actividad de producción de energía eléctrica en régimen especial.

[5] RESOLUCIÓN de 4 de octubre de 2006, por la que se aprueba el procedimiento de operación 3.7 Programación de la generación renovable no gestionable. Ministerio de Industria, Turismo y Comercio, BOE núm. 254, 24 octubre 2006. 